\title{
A rare form of anemia in systemic lupus erythematosus
}

\author{
C.A. Mansoor, R. Narayan
}

Department of Internal Medicine, M.E.S. Medical College, Perinthalmanna, Kerala, India

\begin{abstract}
Mechanisms responsible for anemia in systemic lupus erythematosus (SLE) can be immune or non-immune. A 27-year-old previously healthy woman was admitted with echymotic patches over the lower limbs for six months, multiple joint pain and fatigue for 2 months. She had severe pallor and multiple echymotic patches over the lower limbs. She was diagnosed with SLE with pernicious anemia and iron deficiency anemia. The rare association of SLE with pernicious anemia was reported previously in few patients. Treatment of SLE along with B12 supplementation is necessary for such patients. Since etiology for anemia in SLE can be of various kinds, a detailed workup for identifying the underlying mechanism is necessary.
\end{abstract}

Key words: Lupus; Perinicious anemia.

Reumatismo, 2017; 69 (3): 119-121

\section{INTRODUCTION}

$\mathrm{H}$ ematological abnormalities are common in systemic lupus erythematosus (SLE). Anemia can be seen in about 50\% of patients, with anemia of chronic disease being the most common form (1). Various immune and non-immune mechanisms are responsible for anemia in SLE and include inflammation, renal insufficiency, blood loss, dietary insufficiency, medications, haemolysis, infection, hypersplenism, myelofibrosis, myelodysplasia, and aplastic anemia $(2,3)$. Pernicious anemia and SLE are both disorders of autoimmune etiology. Coexistence of SLE with other autoimmune disorders is common but association of pernicious anemia and SLE is rare.

\section{CASE REPORT}

A 27-year-old previously healthy woman was admitted with echymotic patches over lower limbs for six months, multiple joint pain and fatigue for 2 months. She had menorrhagia for 5 years. She denied history of weight loss, had no sick contacts and had no history of addictions. She had

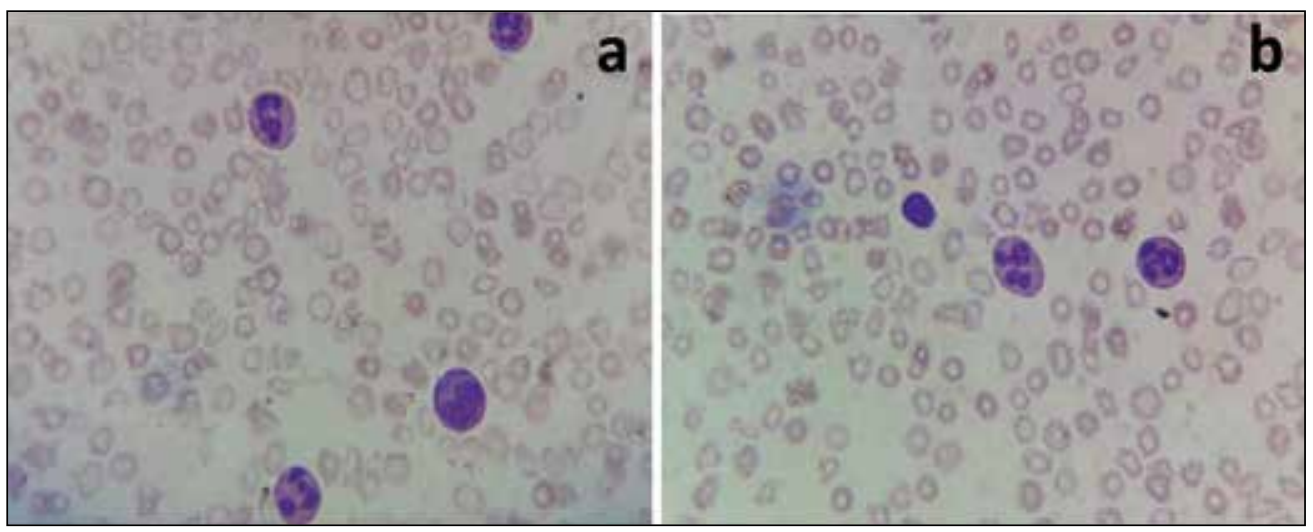

Figure 1 - A and B) Peripheral smear showing moderately hypochromic RBCs, marked anisopoikilocytosis with microcytes, few hypersegmented neutrophils and severely reduced platelet count. $\overline{\text { Corresponding author }}$

C.A. Mansoor

Department of General Medicine,

M.E.S. Medical College,

Perinthalmanna, Kerala

679338, India

E-mail: drcamans@gmail.com 
severe pallor and had multiple echymotic patches over lower limbs. There were no other bleeding manifestations. Hemoglobin was $6.2 \mathrm{~g} / \mathrm{dl}$, total leucocyte count $4600 / \mu l$, platelet count $0.20 \times 10^{9} / \mathrm{L}$, erythrocyte sedimentation rate $60 \mathrm{~mm}$ in $1 \mathrm{~h}$ and $\mathrm{C}$ - reactive protein was normal. The Hematocrit-corrected erythrocyte sedimentation rate was $24 \mathrm{~mm} / \mathrm{h}$.

In the peripheral smear, the RBCs showed moderate hypochromia, marked anisopoikilocytosis with microcytes, macrocytes, pencil shaped cells, macro ovalocytes, elliptocytes, tear drop cells but no hemolysis (Figure 1); WBC's were normal in number with few hypersegmented neutrophils and the platelet count was very low. Urinalysis was normal. Biochemical parameters showed random blood sugar $101 \mathrm{mg} \%$, urea19 mg/dl, creatinine $0.8 \mathrm{mg} / \mathrm{dl}$, sodium
$136 \mathrm{mmol} / \mathrm{l}$, potassium $3.8 \mathrm{mmol} / \mathrm{l}$, AST 37 IU/l, ALT 39 IU/l, alkaline phosphatase $66 \mathrm{IU} / \mathrm{l}$, total bilirubin $1.1 \mathrm{mg} / \mathrm{dl}$, direct bilirubin $0.1 \mathrm{mg} / \mathrm{dl}$, total protein $7.2 \mathrm{~g} / \mathrm{dl}$, albumin $4.4 \mathrm{~g} / \mathrm{dl}$, globulin $2.8 \mathrm{~g} / \mathrm{dl}$. Chest $\mathrm{X}$ Ray and electrocardiogram were normal. Prothrombin time and partial thromboplastin times were normal. HIV, Hepatitis B and Hepatitis $\mathrm{C}$ serologies were negative. Bone marrow aspirate showed hypercellular marrow with erythroid hyperplasia (micronormoblastic and megaloblastic maturation) (Figure 2A and B). Bone marrow biopsy was hypercellular, showing erythroid hyperplasia with micro normoblastic and megaloblastic maturation; the myeloid series showed normal maturation and differentiation, giant metamyelocytes, giant myelocytes and hypersegmanted neutrophils; mild increase in megakaryocytes

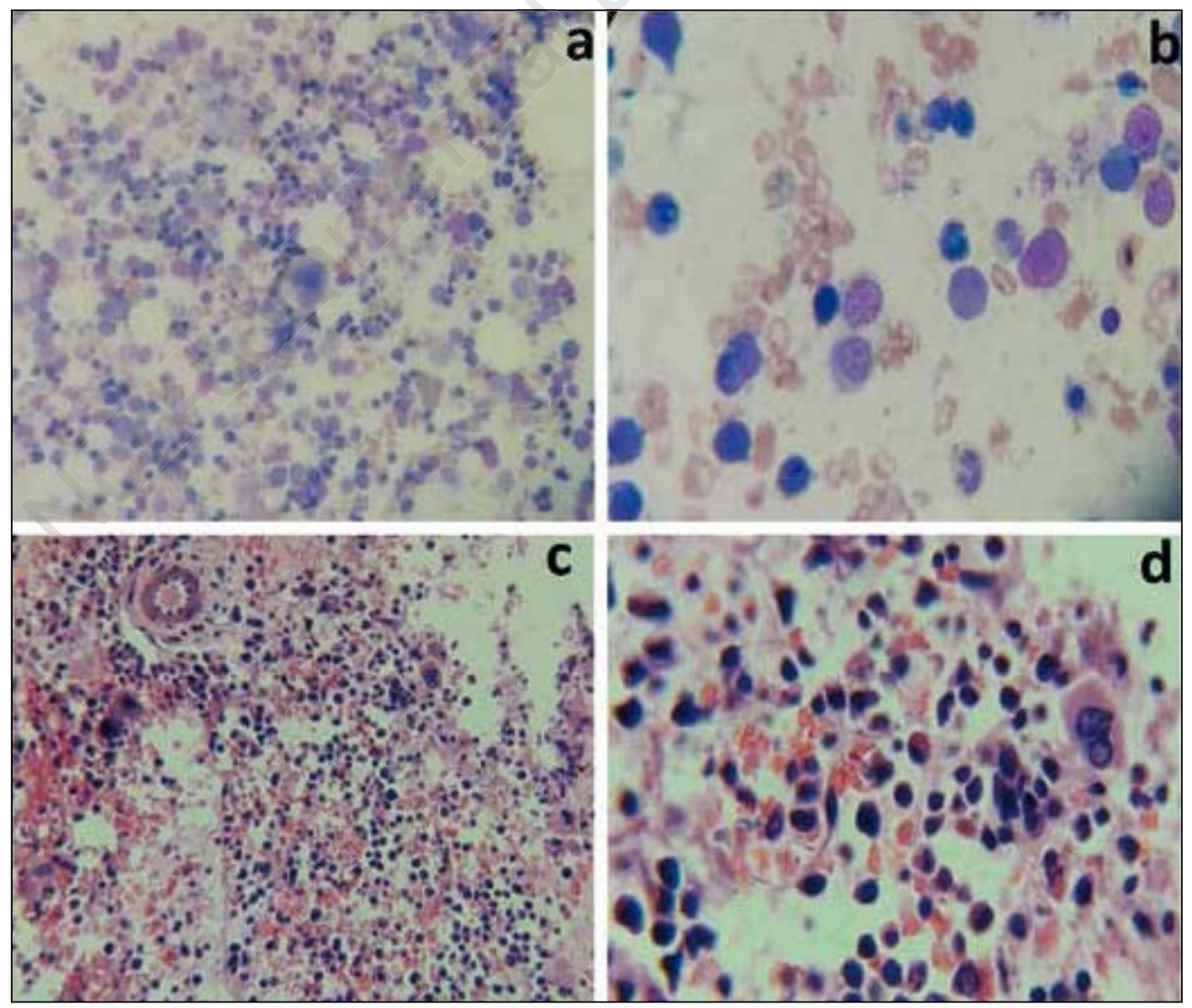

Figure 1 - $A$ and $B$ ) Bone marrow aspirate showing hypercellular marrow with erythroid hyperplasia (micronormoblastic and megaloblastic maturation); C and D) Bone marrow biopsy showing erythroid hyperplasia with micro normoblastic and megaloblastic maturation, hypersegmented neutrophils and mild increase in megakaryocytes. 
with hypolobation (Figure 2C and D). Anti nuclear antibody was positive and anti-double-stranded DNA was strongly positive. $\mathrm{C} 3$ and $\mathrm{C} 4$ levels were low $(53 \mathrm{mg} / \mathrm{dl}$ and $8 \mathrm{mg} / \mathrm{dl}$ respectively). Serum vitamin B12 level was low $(108 \mathrm{pg} / \mathrm{mL})$ and folic acid level was normal. Intrinsic factor antibody was positive. Iron studies showed low ferritin (14.8 nano gram $/ \mathrm{ml})$, low serum iron (34 mcg/dL) and high total iron binding capacity $(540 \mathrm{mcg} / \mathrm{dL})$.

A diagnosis of pernicious anemia and iron deficiency anemia complicating SLE was made based on the investigations. She was started on oral prednisolone $1 \mathrm{mg} / \mathrm{kg}$, steroids, hydroxychloroquine and was also supplemented with hydroxycobalamin, folic acid and iron. When reviewed after three months, hemoglobin was $10.1 \mathrm{~g} / \mathrm{dl}$, total leucocyte count $4800 / \mu \mathrm{l}$ and platelet count $1.30 \times 10^{9} / \mathrm{L}$.

\section{DISCUSSION AND CONCLUSIONS}

SLE is a systemic autoimmune disease with variable multisystem involvement and heterogeneous clinical features, ranging from mild to life-threatening. SLE can appear with hematological manifestations, alone or associated with features of involvement of other systems.

Common hematological abnormalities in SLE include leucopenia, lymphopenia, thrombocytopenia, autoimmune haemolytic anemia, thrombotic thrombocytopenic purpura and myelofibrosis (2). Anemia of chronic disease is the most common form of anemia in SLE; auto-immune hemolytic anemia, iron deficiency anemia, drug-induced myelotoxicity, and anemia due to chronic renal failure are also often detected. Aplastic anemia, pure red cell aplasia, pernicious anemia, myelofibrosis, sideroblastic anemia, haemophagocytic syndrome, and thrombotic microangiopathy occurs less frequently (1).

Iron deficiency anemia (IDA) in SLE patients can be caused by acute or chronic blood loss from the gastrointestinal tract, usually secondary to medications (nonsteroidal anti-inflammatory drugs or steroids), or may be due to excessive menstrual bleeding. Our patient had IDA, mostly secondary to excessive menstrual bleeding. Bone marrow biopsy specimens from patients with SLE having immune mediated bone marrow failure shows hypocellularity, morphological dysplasia, increased fibrosis and necrosis. $T$ cell mediated inhibition of haemopoiesis is the major cause of bone marrow failure in SLE (1). Our patient had bone marrow hypercellularity, erythroid hyperplasia with micro normoblastic and megaloblastic maturation along with low iron and vitamin B12, suggesting nutritional deficiency.

Pernicious anemia is a complex autoimmune disease state caused by impaired absorption of vitamin B12 due to an absence of the gastric glycoprotein, the intrinsic factor (4). SLE can be associated with other autoimmune diseases. The rare association of SLE with pernicious anemia was reported previously in few patients (5-8). Treatment of SLE along with B12 supplementation is necessary for such patients. Since etiology for anemia in SLE can be of various kinds, a detailed workup for identifying the underlying mechanism is necessary.

\section{REFERENCES}

1. Giannouli S, Voulgarelis M, Ziakas PD, Tzioufas AG. Anaemia in systemic lupus erythematosus: from pathophysiology to clinical assessment. Ann Rheum Dis. 2006; 65144-8.

2. Fayyaz A, Igoe A, Kurien BT, et al. Haematological manifestations of lupus. Lupus Sci Med. 2015; 2: e000078.

3. Keeling DM, Isenberg DA. Haematological manifestations of systemic lupus erythematosus. Blood Rev. 1993; 7: 199.

4. Osborne D, Sobczyńska-Malefora A. Autoimmune mechanisms in pernicious anaemia and thyroid disease. Autoimmun Rev. 2015; 14 : 763-8.

5. Benjilali L, Tazi-Mezalek Z, Harmouche H, et al. Pernicious anemia in a young man with systemic lupus erythematosus. Lupus. 2007; 16: 827-9.

6. Durand JM, Cretel E, Juhan V, et al. Systemic lupus erythematosus associated with pernicious anemia. Clin Exper Rheumatol. 1994; 12: 233.

7. Korbet SM, Corwin HL. Pernicious anemia associated with systemic lupus erythematosus. J Rheumatol. 1986; 13: 193-4.

8. Singh A. An uncommon cause of anemia in systemic lupus erythematosus. Int $\mathrm{J}$ Rheum Dis. 2013; 16: 783-5. 